\title{
Severe Physical Intimate Partner Violence and the Mental and Physical Health of U.S. Caribbean Black Women
}

\author{
Krim K. Lacey, PhD, and Dawne M. Mouzon, $\mathrm{PhD}^{2}$
}

\begin{abstract}
Background: Intimate partner violence is a threat to women's health. Relative to other racial/ethnic groups, African American and immigrant women are at an increased risk for violence. However, despite the growing presence of Caribbean Black immigrants in this country, few studies have examined the association between severe physical intimate partner violence (SPIPV) and the health of Caribbean Black women currently residing in the United States. This study examined the mental and physical health of U.S. Caribbean Black women with and without a history of SPIPV. We also explored the role of generational status - first, second, or third-in association with the physical and mental health of abused Caribbean Black women.

Methods: Data from the National Survey of American Life, the largest and the only known representative study on Caribbeans residing in the United States, were analyzed. The World Health Organization (WHO) World Mental Health Composite International Diagnostic Interview (WMH-CIDI) was used to determine DSM-IV mental disorders. The presence of physical health conditions was based on respondents' self-reports of physician diagnoses.

Results: The findings indicate an association between SPIPV and the mental and physical health status of U.S. Caribbean Black women. Rates of physical conditions and mental health disorders were generally higher among women with a history of SPIPV than those without a history. Generational status also played a role in women's health outcomes.

Conclusions: The study has interventions and preventive implications for both detecting and addressing the health needs of U.S. Caribbean Black women who experience severe physical abuse by an intimate partner.
\end{abstract}

\section{Introduction}

I NTIMATE PARTNER VIOLENCE (IPV) remains a public health concern that poses a threat to the general health and well-being of women across different racial and cultural backgrounds, regardless of whether such acts of abuse are of a physical, psychological, or sexual nature. Estimates of IPV among Black women in the United States exceed the rates for women from other racial/ethnic backgrounds. ${ }^{1,2}$ For example, in a study produced by the CDC, $41 \%$ of Black women reported experiencing physical violence by an intimate partner in their lifetime, followed by $35.2 \%$ of Latinas, $31.7 \%$ of White women, and $19.6 \%$ of Asian or Pacific Islander women. ${ }^{3}$

Although there is limited information regarding the victimization of Caribbean Black women currently residing in the United States, population-based studies conducted in Barbados (50\%), Jamaica (45.3\%), and Trinidad and Tobago (45.2\%), (three countries sending of a large number of $\mathrm{Ca}-$ ribbean immigrants to the United States) indicate that physical IPV is an important public health crisis for roughly half of women residing in these countries. ${ }^{4}$ Other studies based on clinical samples found slightly lower lifetime prevalence of IPV in other predominantly Black Caribbean countries (e.g., $38 \%$ in St. Thomas, $28 \%$ in St. Croix). ${ }^{5}$

Recent demographic trends find that the number of $\mathrm{Ca}$ ribbean Black immigrants in the U.S. increased threefold between 1980 and 2009, ${ }^{6}$ making them one of the fastest growing subgroups in the United States. Given their increasing representation in the U.S. society and alarming rates of IPV, it becomes particularly relevant to understand the health risks and consequences of IPV among Caribbean Black women residing in the United States.

Extensive studies have found that women who experience IPV have poorer physical and mental health outcomes. For example, among the myriad of conditions, women with a history of IPV have been found to have higher prevalence of

\footnotetext{
${ }^{1}$ Program for Research on Black Americans, Institute for Social Research, University of Michigan, Ann Arbor, Michigan.

${ }^{2}$ Edward J. Bloustein School of Planning and Public Policy, Institute for Health, Health Care Policy, and Aging Research, Rutgers, The State University of New Jersey, New Brunswick, New Jersey.
} 
asthma, diabetes, frequent headaches, difficulty sleeping, chronic pain, HIV, activity limitations, and poorer self-rated physical health. ${ }^{7-13}$

A well-established body of literature also associates intimate partner victimization with poor mental health. Studies have consistently shown a positive relationship between IPV and various mood, anxiety, and substance disorders. ${ }^{14}$ These studies have especially found increased risk for depression, alcohol use and abuse, posttraumatic stress disorders (PTSD), and suicidal tendencies among victims of IPV., $7,8,15$

Yet the negative health outcomes associated with IPV are not equally borne across women of varying racial/ethnic backgrounds. Black women of Caribbean descent, like other Blacks in the United States, face additional structural and environmental stressors and poverty that not only increase their risk for IPV but also poor health conditions in general. ${ }^{16-18}$. Although past research has documented poor health outcomes among abused women and Black women as a whole, very little research has investigated the association between IPV and the health outcomes of Caribbean Black women residing in the United States.

A study using a clinical convenience sample exploring these relationships among Caribbeans living in Baltimore, $\mathrm{MD}$ and in their home countries (e.g., St. Croix and St. Thomas) found that physical IPV was associated with disordered eating. ${ }^{19}$ IPV was also associated with PTSD and depression among Caribbean Black women in these samples; moreover, severe IPV was associated with more negative mental health outcomes than less severe forms of IPV. ${ }^{19}$ These findings were supported in a national study that found associations between mental disorders and IPV.${ }^{15}$ However, comparative population-based studies are needed to disentangle the mental and physical health risk of IPV among Caribbean Black women who might already be predisposed to poor health outcomes.

\section{The present study}

In this study, we assessed the mental and physical health of U.S. Caribbean Black women, with emphasis on the role of severe physical intimate partner violence (SPIPV). We contribute to past research in two critical ways. First, we use a nationally representative sample of U.S. Caribbean Black women, to assess extensive mental and physical health conditions. Second, we explore whether generational status (first, second, or third) is differentially associated with physical and mental health outcomes among Caribbean Black women. The findings have important implications both for identifying Caribbean Black women who may be at increased risk of poor health outcomes associated with SPIPV and creating culturally tailored interventions for SPIPV survivors.

\section{Methods}

Cross-sectional data from the National Survey of American Life (NSAL) were used to address the research objective. The NSAL, part of the National Institute of Mental Health's Collaborative Psychiatric Epidemiological Surveys initiative, is the most detailed study of the mental and physical health of Black adults living in the United States. Moreover, it is the first known national study of Blacks of Caribbean descent. ${ }^{20-22}$ Multistage probability sampling techniques were used to generate the sample of 6082 participants, including 3570 African Americans, 891 non-Hispanic Whites, and 1623 Caribbean Blacks.

The national sample of Caribbean Blacks was identified from two overlapping area probability sampling frames. A total of 266 Caribbean Blacks were interviewed in the NSAL core sample. The remaining 1357 Caribbean Black participants were selected from an area probability sample of housing units from high-density Caribbean areas in the United States. ${ }^{20}$ Eight primary areas were selected in the following five states and the district of Washington, DC that comprise $80 \%$ of the Caribbean population: New York, New Jersey, Florida, Connecticut, and Massachusetts. Caribbean participants included in the sample self-identified as $\mathrm{Ca}$ ribbean Black, answered affirmatively when asked if they were of West Indian or Caribbean descent, were from a Caribbean area county, or had a parent or at least one grandparent who was born in a Caribbean area county.

Face-to-face interviewing was the main method of data collection, with a smaller proportion (14\%) of interviews conducted by phone. Data were collected between February 2001 and June 2003, using a computer-assisted instrument. At the beginning of each interview, an overview of the study purpose and consent rights were presented. Interviews with Caribbean Black participants typically lasted an average of 2 hours and 43 minutes. Participants were compensated with a $\$ 50$ honorarium for completing the interview. The response rate generated for the Caribbean sample was $77.7 \%$. We specifically focused on U.S. Caribbean Black women in this study, representing 949 of the participants in the total Caribbean sample. In total, 113 Black women of Caribbean descent sampled reported having experienced lifetime severe physical violence by an intimate partner.

\section{Measures}

Mental health. The mental disorders covered in the NSAL are based on the World Health Organization (WHO), World Mental Health Composite International Diagnostic Interview (WMH-CIDI), a fully structured lay-administered interview used to assess a wide range of Diagnostic and Statistical Manual (DSM) IV mental disorders. The following lifetime mental disorders were examined: mood (any, major depressive episode [MDE], dysthymia, major depressive disorder [MDD], bipolar); anxiety (any, panic, agoraphobia, generalized anxiety disorder [GAD], obsessive compulsive disorder [OCD], PTSD); substance (any, alcohol abuse, alcohol dependence, drug abuse, drug dependence); eating (any, anorexia, bulimia, binge); and "any" overall disorder. We created a composite measure of "any disorder," a variable that was coded 1 if respondents met criteria for any of the aforementioned disorders, and 0 if not. Suicidal ideation was addressed with the question, "Have you ever seriously thought about committing suicide?" Suicide attempts were gauged with the question, "Have you ever attempted suicide?" $(1=$ yes, $0=$ no $)$.

Physical health. Participants were asked if "ever," in their lifetime, they were told by a doctor or health professional that they had any of a list of physical health problems, including arthritis, ulcers, cancer, high blood pressure, diabetes, liver problems, kidney problems, stroke, asthma, lung disease, blood circulation problems, sickle cell, heart trouble, HIV or AIDS, 
glaucoma, tuberculosis, fertility problems, and osteoporosis. We also created a composite of the lifetime aforementioned conditions representing "any" physical conditions $(1=$ yes, $0=$ no).

Severe physical intimate partner violence. Lifetime SPIPV was addressed with the question, "Were you ever badly beaten up by a spouse or a romantic partner?" (1=yes, $0=$ no). The lifetime IPV measure used in this study was compared to the U.S. National Comorbidity Survey Replication (NCS-R) dichotomously defined severe partner violence Conflict Tactic Scale (CTS) measure within the Collaborative Psychiatric Epidemiological Study, and was found to have a fair association across two different approaches to estimating agreement $(\mathrm{OR}=4.5, p<0.001$; AUC $>0.06){ }^{15}$

Sociodemographic variables. The sociodemographic predictors included the following: age (e.g., 18-24; 25-34; 35-49; 50-64; and 65 and older), marital status (e.g., married, partnered, separated or divorced, widowed; never married), education (e.g., less than high school; high school graduates, some college; and college), household income (e.g., less than $\$ 25,000 ; \quad \$ 25,000-\$ 34,999 ; \quad \$ 35,000-\$ 49,999 ; \quad \$ 50,000$ $\$ 74,999$; and $\$ 75,000$ and over), and employment status (e.g., employed; unemployment; not in the labor force).

Generational status. First-generation respondents were the foreign born individuals who had directly migrated to the United States from the Caribbean region. Second generation respondents were U.S.-born respondents with at least one Caribbean immigrant parent. Third generation participants comprised U.S.-born respondents whose parents were born in the U.S., but had at least one Caribbean-born grandparent.

Discrimination. Everyday discrimination is an index comprised of ten items including the following: "You are treated with less courtesy than other people"; "You are treated with less respect than other people"; "You receive poorer service than other people at restaurants and stores"; "People act as if they think you are not smart"; "People act as if they are afraid of you"; "People act as if they think you are dishonest"; "People act as if they are better than you are"; "You are called names or insulted"; "You are threatened or harassed"; and "You are followed around stores." Responses were coded on a five-point Likert scale ranging from never to almost every day. Altogether, the measures had an internal consistency of 0.89 . The index was then dichotomized such that $0=$ no experiences of discrimination and $1=$ one or more experiences of discrimination.

\section{Analytic procedure}

Cross-tabulations using the $\chi^{2}$ analytic procedure were used to assess percent differences in health between women with and without a history of SPIPV in general and by generational status. We further used multivariate logistic regression analytic procedure to examine the influence of key predictors (e.g., SPIPV, generational status, discrimination, and sociodemographic variables) on the mental and physical health of Caribbean Black women. In these analyses, adjusted odds ratio estimates and confidence intervals are presented.
We specifically focused on "any" mental and physical conditions due to the low number of cases within specific health categories. Because of the complex nature of the sample, techniques for calculating complex design-based estimates of variance were applied. Statistical significance was set at $\alpha=0.05$.

\section{Results}

\section{Sample description}

Table 1 displays descriptive statistics for the analytic sample $(n=949)$. Roughly half of respondents were between the ages of 35 and 64, with no age differences between Caribbean Black women with and without a history of SPIPV.

Table 1. Descriptive Statistics for U.S. Caribbean Black Women With and Without History

of Severe Physical Intimate Partner Violence, 2001-2003 National Survey of American Life

\begin{tabular}{cccc}
\hline & No history & History of & \\
of SPIPV & SPIPV & Group \\
Characteristics & $\mathrm{n}=836$ & $\mathrm{n}=113$ & difference \\
\hline
\end{tabular}

Age of respondents $(\%)$

$18-24$

$25-34$

$35-49$

$50-64$

$>65$

Marital status (\%)

Married

Partnered

Separated or divorced

Widowed

Never married

Education $(\%)$

Less than HS

HS graduate

Some college

College

Household income $(\%)$

$<\$ 25,000$

18.7

19.7

34.8

16.1

10.8

25.8

39.5

14.1

28.9

11.2

20.3

6.6

33.1

8.1

$p=0.544$

$\$ 25,000-\$ 34,999$

$\$ 35,000-\$ 49,999$

$\$ 50,000-\$ 74,999$

$>\$ 75,000$

Employed status (\%)

Employed

Unemployed

Not in the labor force

Home ownership (\%)

Own home

Rented

20.3

28.1

29.8

21.9

21.2

15.7

31.0

5.3

26.8

$p=0.332$

Region (\%)

Northeast

Midwest

South

36.5

15.3

17.6

17.3

13.3

25.8

43.4

24.2

6.6

$p=0.010^{\mathrm{a}}$

West

72.1

9.5

18.4

58.4

26.2

5.4

7.0

2.9

$p=0.002^{\mathrm{b}}$

60.5

16.7
22.8

46.8

53.2

17.0

83.0

$p=0.375$

${ }^{\mathrm{a}} p<0.05$.

${ }^{\mathrm{b}} p<0.01$.

${ }^{c} p<0.001$.

SPIPV, severe physical intimate partner violence; HS, high school. 
There were also no significant differences in marital status between the groups, although women without a history of SPIPV tended never to marry compared to women with a history of SPIPV who were separated or divorced. However, U.S. Caribbean Black women with a history of SPIPV were far less likely to have a college education than Caribbean Black women without a history of SPIPV (6.6\% vs. $21.9 \%$, $p<0.01)$. Similarly, women with a history of SPIPV were more likely to have lower household income $(<\$ 25,000)$ than those without a history of SPIPV ( $58.4 \%$ vs. $36.5 \% ; p<0.01)$. Differences between the populations, however, were not found for employment status. A majority of the participants in both populations were employed, although fewer women with SPIPV were employed. Also, a significantly lower percentage of women with a history of SPIPV owned homes compared to women without a history of SPIPV (17.0\% vs. $46.8 \%, p<0.001)$. Finally, although a majority of participants resided in the Northeast, there were no regional differences between women with and without a history of SPIPV.

\section{SPIPV, Lifetime mental disorders and the physical health of Caribbean Black women}

Table 2 shows the prevalence of lifetime mental disorders among Black Caribbean women with and without a history of SPIPV. About half as many U.S. Caribbean Black women with a history of SPIPV met criteria for any mood disorder than their counterparts without a history of SPIPV (14.6\% vs. $33.6 \%, p<0.01)$. MDE was also more than twice as high among women with a history of SPIPV $(28.5 \%$ vs. $13.5 \%$, $p<0.05)$ and bipolar disorder was more than 10 times higher among women with a history of SPIPV than those without a history of SPIPV $(12.4 \%$ vs. $1.3 \%, p<0.001)$. Differences were not found for dysthymia and MDDs between the populations.

Differences were found between groups for all anxiety disorders examined. Higher rates among Caribbean Black women with a history of SPIPV were especially noted for any anxiety $(38.3 \%$ vs. $14.4 \%, p<0.001)$, PTSD $(28.9 \%$ vs. $5.7 \%, p<0.001)$, and panic disorder $(11.9 \%$ vs. $1.9 \%$, $p<0.001)$. Relative to Caribbean Black women without a history of SPIPV, Caribbean Black women with a history of SPIPV also had higher lifetime prevalence of obsessivecompulsive disorder ( $4.6 \%$ vs. $0.6 \%, p<0.01)$, GAD $(9.9 \%$ vs. $2.2 \%, p<0.05)$, and agoraphobia $(4.8 \%$ vs. $2.7 \%$, $p<0.05$ ).

Women with a history of SPIPV also differed from their non-abused counterparts in terms of substance disorders. For example, rates of any substance disorder $(6.1 \%$ vs. $2.2 \%$, $p<0.05)$, alcohol abuse (5.5\% vs. $1.8 \%, p<0.05)$, and drug dependence $(3.7 \%$ vs. $0.7 \%, p<0.01)$ were almost threefold higher among Caribbean Black women with a history of SPIPV than their counterparts with no history of SPIPV. However, differences were not observed for alcohol dependence or drug abuse.

Rates of eating disorders were generally higher for those with a history of SPIPV than those without such a history. In particular, the rate for any eating disorder for women with a history of SPIPV exceeded that of women without a SPIPV history by more than threefold $(19.5 \%$ vs. $6.1 \%, p<0.05)$. More than a twofold difference was found between the two
Table 2. Lifetime Prevalence of Mental Disorders Among U.S. Caribbean Black Women With and Without a History of Severe Physical Intimate Partner Violence, 2001-2003 National Survey of American Life

\begin{tabular}{|c|c|c|c|}
\hline Disorders & $\begin{array}{l}\text { No history } \\
\text { of SPIPV \% }\end{array}$ & $\begin{array}{l}\text { History of } \\
\text { SPIPV \% }\end{array}$ & $\begin{array}{l}\text { Difference } \\
\chi^{2} / \mathrm{p} \text { value }\end{array}$ \\
\hline \multicolumn{4}{|l|}{ Mood disorders } \\
\hline Any & 14.6 & 33.6 & $46.83^{\mathrm{a}}$ \\
\hline MDE & 13.5 & 28.5 & $31.79^{b}$ \\
\hline Dysthymia & 2.01 & 6.04 & 12.13 \\
\hline $\begin{array}{l}\text { Major depressive } \\
\text { disorder }\end{array}$ & 13.1 & 21.3 & 9.86 \\
\hline Bipolar disorder & 1.3 & 12.4 & $84.62^{c}$ \\
\hline \multicolumn{4}{|l|}{ Anxiety disorder } \\
\hline Any & 14.4 & 38.3 & $72.19^{c}$ \\
\hline Panic disorder & 1.9 & 11.9 & $60.98^{c}$ \\
\hline Agoraphobia & 2.7 & 4.8 & $2.90^{\mathrm{b}}$ \\
\hline $\begin{array}{l}\text { Generalized anxiety } \\
\text { disorder }\end{array}$ & 2.2 & 9.9 & $35.93^{\mathrm{b}}$ \\
\hline $\begin{array}{l}\text { Obsessive-compulsive } \\
\text { disorder }\end{array}$ & 0.6 & 4.6 & $28.04^{\mathrm{a}}$ \\
\hline PTSD & 5.7 & 28.9 & $125.83^{c}$ \\
\hline \multicolumn{4}{|l|}{ Substance disorder } \\
\hline Any & 2.2 & 6.1 & $10.32^{\mathrm{b}}$ \\
\hline Alcohol abuse & 1.8 & 5.5 & $11.26^{\mathrm{b}}$ \\
\hline Alcohol dependence & 0.7 & 3.4 & 12.57 \\
\hline Drug abuse & 1.8 & 3.9 & 4.10 \\
\hline Drug dependence & 0.7 & 3.7 & $15.76^{\mathrm{a}}$ \\
\hline \multicolumn{4}{|l|}{ Eating disorder } \\
\hline Any & 6.1 & 19.5 & $45.75^{\mathrm{b}}$ \\
\hline Anorexia & na & na & na \\
\hline Bulimia & 2.8 & 7.9 & $14.78^{\mathrm{b}}$ \\
\hline Binge eating & 6.1 & 19.5 & $45.75^{\mathrm{b}}$ \\
\hline \multicolumn{4}{|l|}{ Suicide } \\
\hline Attempts & 1.4 & 12.7 & $88.17^{\mathrm{c}}$ \\
\hline Ideation & 8.6 & 27.2 & $64.98^{\mathrm{a}}$ \\
\hline Any disorder & 29.6 & 60.7 & $79.26^{\mathrm{c}}$ \\
\hline
\end{tabular}

"na" indicates there were insufficient data.

${ }_{\mathrm{a}}^{\mathrm{a}} p<0.01$.

${ }^{\mathrm{b}} p<0.05$.

${ }^{c} p<0.001$.

MDE, major depressive episode; PTSD, posttraumatic stress disorders.

groups for bulimia $(7.9 \%$ vs. $2.8 \%, p<0.05)$ and more than a threefold difference in rates of binge eating was also detected $(19.5 \%$ vs. $6.1 \%, p<0.05)$.

A similar trend was observed for suicide attempts and ideation between populations. Caribbean Black women with a history of SPIPV attempted suicide at around 10 times the rate of women who did not experience SPIPV (12.7\% vs. $1.4 \%, p<0.001)$. Rates of suicide ideation among women with a history of SPIPV significantly exceeded that of women who lacked an SPIPV history by more than threefold (27.2\% vs. $8.6 \%, p<0.01$ ). In addition, rates of "any" overall mental disorder among women with a history of SPIPV were more than twice as high as those without a history of SPIPV (60.7\% vs. $29.6 \%, p<0.001$ ).

Table 3 displays the prevalence of various physical health conditions among Caribbean Black women with and without a history of SPIPV. Of the physical health conditions explored, significant differences were found in relation to five physical health indicators. Specifically, the rate of arthritis 
Table 3. Lifetime Prevalence of Physical Health Conditions Among U.S. Caribbean Black Women With and Without a History of Severe Physical Intimate Partner Violence, 2001-2003 National Survey of American Life

\begin{tabular}{lccc}
\hline Conditions & $\begin{array}{c}\text { No History } \\
\text { of SPIPV } \%\end{array}$ & $\begin{array}{c}\text { History of } \\
\text { SPIPV } \%\end{array}$ & $\begin{array}{c}\text { Differences } \\
\chi^{2} / \mathrm{p} \text { value }\end{array}$ \\
\hline Arthritis & 15.5 & 26.7 & $8.99^{\mathrm{a}}$ \\
Ulcers & 3.9 & 12.9 & 17.20 \\
Cancer & 4.5 & 5.0 & 0.06 \\
High blood pressure & 26.8 & 38.5 & 6.69 \\
Diabetes & 12.02 & 7.74 & 3.32 \\
Liver problems & 0.8 & 3.7 & $7.31^{\mathrm{a}}$ \\
Kidney problems & 1.8 & 6.0 & $8.07^{\mathrm{b}}$ \\
Stroke & 2.8 & 1.2 & 1.03 \\
Asthma & 10.9 & 20.4 & 8.60 \\
Lung disease & 0.7 & 1.0 & 0.19 \\
Blood circulation & 2.6 & 7.8 & 8.35 \\
$\quad$ problems & & & \\
Sickle cell & 3.7 & 4.0 & 0.03 \\
Heart trouble & 5.1 & 6.4 & 0.38 \\
HIV or AIDS & 0.1 & 1.3 & $5.69^{\mathrm{b}}$ \\
Glaucoma & 2.0 & 4.3 & 2.48 \\
Fertility problems & 5.2 & 14.8 & 15.30 \\
Osteoporosis & 1.8 & 6.1 & 8.13 \\
Tuberculosis & 1.4 & na & 2.48 \\
\hline
\end{tabular}

"na" indicates there were insufficient data.

${ }^{\mathrm{a}} p<0.05$.

${ }^{\mathrm{b}} p<0.01$.

was higher for women with a history of SPIPV than those without a SPIPV history $(26.7 \%$ vs. $15.5 \%, p<0.05)$. Likewise, women with a history of SPIPV had more than four times the risk of liver problems than women without a SPIPV history $(3.7 \%$ vs. $0.8 \%, p<0.05)$. Kidney problems were thrice more prevalent among women with a history of SPIPV than those without $(6.0 \%$ vs. $1.8 \%, p<0.01)$. Although there was low prevalence of HIV/AIDS overall, rates were nonetheless higher among women with a history of SPIPV than those without such a history $(1.3 \%$ vs. $0.1 \%, p<0.01)$.

While failing to reach conventional statistical significance levels, it is important to note that the rates of the following conditions were marginally higher for Caribbean Black women with a history of SPIPV than their counterparts without a SPIPV history: high blood pressure $(38.5 \%$ vs. $26.8 \%$, $p=0.053)$, blood circulation problems $(7.8 \%$ vs. $2.6 \%$, $p=0.051)$, fertility problems $(14.8 \%$ vs. $5.2 \%, p=0.065)$, and osteoporosis $(6.1 \%$ vs. $1.8 \%, p=0.086)$.

\section{Lifetime mental and physical health of Caribbean Black women: the roles of SPIPV and generational status}

Table 4 presents rates of lifetime mental disorders for women with and without a history of SPIPV by generational status. Differences in prevalence rates were observed within the first generation for bipolar disorder (8.9\% vs. $0.8 \%$, $p<0.001$ ), with higher rates among those having a history of SPIPV than those without a history. These differences were also found among third-generation women. Again, higher rates were found among women with a history of SPIPV $(14.0 \%$ vs. $0.6 \%, p<0.01)$ relative to women without a history of SPIPV.
Group differences were also found for certain anxiety disorders. Notably, observed differences were found for panic disorder among first- $(9.0 \%$ vs. $1.9 \%, p<0.05)$, second( $16.0 \%$ vs. $2.1 \%, p<0.01)$, and third- $(13.5 \%$ vs. $1.5 \%$, $p<0.001)$ generation women, with higher rates among women with a history of SPIPV compared to women without such history. Differences between groups were further found for women who suffered from PTSD. Within first- $(27.8 \%$ vs. $5.8 \%, p<0.001)$, second- $(20.6 \%$ vs. $6.0 \%, p<0.01)$, and third-generation $(38.0 \%$ vs. $5.0 \%, p<0.001)$ women, higher rates were found among women with a history of SPIPV than without a history of SPIPV. Similar results were also observed among first-generation Caribbean Black women with a history of SPIPV who met criteria for agoraphobia $(7.5 \%$ vs. $1.2 \%, p<0.05)$, OCD ( $7.2 \%$ vs. $0.5 \%, p<0.001)$, and any anxiety disorder $(35.5 \%$ vs. $11.8 \%, p<0.001)$.

Higher prevalence rates of alcohol abuse were more apparent for women with a history of SPIPV than those without a history among first- $(3.9 \%$ vs. $0.6 \%, p<0.01)$ and secondgeneration $(10.7 \%$ vs. $2.4 \%, p<0.01)$ Caribbean Black women. This was also true for women who met criteria for any substance disorder among first- $(3.9 \%$ vs. $0.7 \%, p<0.01)$ and second-generation $(13.0 \%$ vs. $2.9 \%, p<0.05)$ Caribbean Black women. For other substance disorders such as alcohol (7.2\% vs. $0.2 \%, p<0.001)$ and drug dependency $(8.2 \%$ vs. $1.0 \% p<0.01)$, group differences were observed among second-generation participants; women with a history of SPIPV exhibiting higher rates than their counterparts.

The analysis further showed differences between women with and without a history of violence in relation to eating disorder based on generational status. These differences were found for first- $(19.6 \%$ vs. $3.2 \%, p<0.01)$ and second$(34.6 \%$ vs. $6.6 \%, p<0.05)$ generation women who met criteria for binge eating, with higher rates among women who experienced SPIPV. Differences were also noted for bulimia $(15.2 \%$ vs. $1.7 \%, p<0.01)$ among first-generation participants. For any eating disorder, differences were additionally found between first- $(19.6 \%$ vs. $3.2 \%, p<0.01)$, second$(34.6 \%$ vs. $6.6 \%, p<0.05)$, and third- $(19.5 \%$ vs. $6.1 \%$, $p<0.05)$ generation women, with higher rates among women with a history of SPIPV.

For women who attempted suicide, rates were found to be higher among first- $(9.6 \%$ vs. $0.6 \%, p<0.001)$ and third$(20.6 \%$ vs. $2.8 \%, p<0.01)$ generation participants with a history of SPIPV relative to those without a history of violence. However, for suicidal ideation, higher rates were found among first-generation women with a history of SPIPV than women without such a history $(25.8 \%$ vs. $5.6 \%$, $p<0.001$ ).

Overall, there were differences in rates of "any" mental disorder between women with and without a history of SPIPV by generation status, with more apparent differences between first- $(45.0 \%$ vs. $23.4 \%, p<0.05)$ and third- $(96.0 \%$ vs. $58.5 \%, p<0.05)$ generation Caribbean Black women. Taken together, the results showed that mental disorders were most prevalent among second- and third-generation victims of abuse compared with their first-generation counterparts.

As indicated in Table 5, there were noted differences in physical health conditions by generation status between women with and without a history of SPIPV. Among firstgeneration Caribbean Black women, group differences in the rate of health conditions were found for such conditions as 
Table 4. Bivariate Association of Lifetime Mental Disorders Among U.S. Caribbean Black Women With and Without A History of Severe Physical Violence by Generation Status, 2001-2003 National Survey of American Life

\begin{tabular}{|c|c|c|c|c|c|c|c|c|c|}
\hline \multirow[b]{2}{*}{ Disorders } & \multicolumn{3}{|c|}{ First generation } & \multicolumn{3}{|c|}{ Second generation } & \multicolumn{3}{|c|}{ Third generation } \\
\hline & $\begin{array}{c}\text { No history } \\
\text { of SPIPV }\end{array}$ & $\begin{array}{l}\text { History } \\
\text { of SPIPV }\end{array}$ & $\begin{array}{l}\chi^{2} / \mathrm{p} \\
\text { value }\end{array}$ & $\begin{array}{c}\text { No history } \\
\text { of SPIPV }\end{array}$ & $\begin{array}{l}\text { History of } \\
\text { SPIPV }\end{array}$ & $\begin{array}{l}\chi^{2} / \mathrm{p} \\
\text { value }\end{array}$ & $\begin{array}{c}\text { No history } \\
\text { of SPIPV }\end{array}$ & $\begin{array}{l}\text { History } \\
\text { of SPIPV }\end{array}$ & $\begin{array}{l}\chi^{2} / \mathrm{p} \\
\text { value }\end{array}$ \\
\hline \multicolumn{10}{|l|}{ Mood disorders } \\
\hline Any & 10.9 & 20.6 & 12.77 & 18.7 & 30.2 & 16.05 & 27.7 & 59.3 & 123.84 \\
\hline MDE & 10.3 & 20.0 & 13.25 & 15.4 & 26.4 & 17.08 & 27.7 & 45.3 & 40.52 \\
\hline Dysthymia & 2.2 & 8.3 & 20.35 & 1.7 & 3.9 & 4.89 & 0.9 & 4.0 & 16.46 \\
\hline MDD & 9.9 & 11.7 & 0.46 & 15.4 & 12.7 & 1.11 & 27.1 & 45.3 & 43.83 \\
\hline Bipolar & 0.8 & 8.9 & $60.50^{\mathrm{a}}$ & 3.3 & 17.5 & 80.31 & 0.6 & 14.0 & $133.84^{b}$ \\
\hline \multicolumn{10}{|l|}{ Anxiety disorders } \\
\hline Any & 11.8 & 35.5 & $60.77^{\mathrm{a}}$ & 14.2 & 28.4 & 29.28 & 29.7 & 51.5 & 59.25 \\
\hline Panic & 1.9 & 9.0 & $29.03^{c}$ & 2.1 & 16.0 & $100.66^{b}$ & 1.5 & 13.5 & $96.84^{\mathrm{a}}$ \\
\hline Agoraphobia & 1.2 & 7.5 & $32.51^{\mathrm{c}}$ & 1.2 & 4.8 & 15.12 & 13.6 & 0.0 & 57.14 \\
\hline GAD & 1.8 & 8.8 & 29.19 & 1.4 & 5.5 & 17.91 & 5.9 & 15.5 & 34.88 \\
\hline OCD & 0.5 & 7.2 & $60.87^{\mathrm{a}}$ & 1.0 & 2.3 & 2.64 & 0.4 & 2.0 & 10.02 \\
\hline PTSD & 5.8 & 27.8 & $96.07^{\mathrm{a}}$ & 6.0 & 20.6 & $57.66^{\mathrm{b}}$ & 5.0 & 38.0 & $271.59^{\mathrm{a}}$ \\
\hline \multicolumn{10}{|l|}{ Substance disorders } \\
\hline Any & 0.7 & 3.9 & $15.79^{\mathrm{b}}$ & 2.9 & 13.0 & $50.40^{c}$ & 9.5 & 4.0 & 11.34 \\
\hline Alcohol abuse & 0.6 & 3.9 & $17.42^{\mathrm{b}}$ & 2.4 & 10.7 & $41.44^{\mathrm{b}}$ & 7.3 & 4.0 & 5.17 \\
\hline Alcohol dependency & 0.1 & 1.3 & 8.45 & 0.2 & 7.2 & $90.80^{\mathrm{a}}$ & 5.4 & 4.0 & 1.17 \\
\hline Drug abuse & 0.5 & 1.8 & 4.29 & 2.2 & 8.2 & 24.71 & 8.1 & 4.0 & 7.31 \\
\hline Drug dependency & 0.3 & 1.3 & 3.59 & 1.0 & 8.2 & $54.80^{\mathrm{c}}$ & 2.4 & 4.0 & 2.63 \\
\hline \multicolumn{10}{|l|}{ Eating disorders } \\
\hline Any & 3.2 & 19.6 & $85.41^{\mathrm{b}}$ & 6.6 & 34.6 & $169.28^{c}$ & 6.1 & 19.5 & $25.28^{\mathrm{c}}$ \\
\hline Anorexia & na & na & na & na & na & na & na & na & na \\
\hline Bulimia & 1.7 & 15.2 & $91.85^{\mathrm{b}}$ & 0.6 & 2.3 & 6.39 & 12.9 & 0.0 & 54.19 \\
\hline Binge eating & 3.2 & 19.6 & $85.41^{\mathrm{b}}$ & 6.6 & 34.6 & $169.28^{\mathrm{c}}$ & 21.8 & 6.2 & 46.86 \\
\hline \multicolumn{10}{|l|}{ Suicide } \\
\hline Attempts & 0.6 & 9.6 & $85.27^{\mathrm{a}}$ & 2.7 & 9.6 & 27.59 & 2.8 & 20.6 & $136.75^{b}$ \\
\hline Ideation & 5.6 & 25.8 & $84.25^{\mathrm{a}}$ & 12.3 & 37.8 & 97.47 & 18.7 & 20.6 & 0.68 \\
\hline Any mental disorder & 23.4 & 45.0 & $34.98^{\mathrm{c}}$ & 32.6 & 51.5 & 30.69 & 58.5 & 96.0 & $183.58^{\mathrm{c}}$ \\
\hline
\end{tabular}

arthritis $(33.5 \%$ vs. $14.3 \%, p<0.01)$, ulcers $(15.1 \%$ vs. $3.1 \%$, $p<0.01)$, high blood pressure $(50.3 \%$ vs. $27.4 \%, p<0.01)$, and poor blood circulation $(9.4 \%$ vs. $2.5 \%, p<0.05)$. Among second-generation women, a similar pattern was found for kidney problems $(21.1 \%$ vs. $1.7 \%, p<0.01)$, HIV/AIDS (5.7\% vs. $0.2 \%, p<0.001)$, and osteoporosis $(15.5 \%$ vs. $1.2 \%, p<0.01)$. In all cases, rates were higher for women with a history of SPIPV than those without.

Finally, third-generation women with a history of SPIPV had significantly higher rates of problems with sickle-cell disease than their counterparts without such a history $(13.5 \%$ vs. $0.8 \%, p<0.01)$. While these differences were also observed between groups for individuals who reported having had a stroke ( $17 \%$ vs. $0.7 \%, p<0.01)$, an opposite pattern was found. In fact, women without a history of SPIPV had higher rates than women with a history of SPIPV. Nonetheless, participants with a history of SPIPV tended to have higher rates of these health conditions than women without a history of SPIPV. Also, with few exceptions, higher prevalence of physical health problems trended toward second- and third- generation immigrants reporting abuse compared to those with first-generation statuses.

\section{Multivariate analysis of any mental health and physical conditions}

Multivariate analysis revealed an association between SPIPV and "any" mental disorder when controlling for other factors (Table 6). Specifically, the odds of mental disorder increased almost three and a half times $(\mathrm{AOR}=3.48$, $p<0.001)$ among abused Caribbean Black women compared to those who did not experience SPIPV. Third-generation women were also found to have higher odds of mental health conditions, increasing about six and a half times $(\mathrm{AOR}=$ 6.54, $p<0.001)$ compared with first-generation Caribbean Black women.

Other factors associated with any mental health conditions included age and household income. Women between the ages of 50 to $64(\mathrm{AOR}=0.10, p<0.001)$ and 65 and older $(\mathrm{AOR}=0.20, p<0.05)$ were at lower odds for mental 
Table 5. Bivariate Association of Physical Health Conditions Among U.S. Caribbean Black Women With and Without A History of Severe Physical Violence, by Generation Status, 2001-2003 National Survey of American LifE

\begin{tabular}{|c|c|c|c|c|c|c|c|c|c|}
\hline \multirow[b]{2}{*}{ Conditions } & \multicolumn{3}{|c|}{ First generation } & \multicolumn{3}{|c|}{ Second generation } & \multicolumn{3}{|c|}{ Third generation } \\
\hline & $\begin{array}{c}\text { No history } \\
\text { of SPIPV }\end{array}$ & $\begin{array}{l}\text { History } \\
\text { of SPIPV }\end{array}$ & $\begin{array}{c}\chi^{2} / \mathrm{p} \\
\text { value }\end{array}$ & $\begin{array}{c}\text { No history } \\
\text { of SPIPV }\end{array}$ & $\begin{array}{l}\text { History } \\
\text { of SPIPV }\end{array}$ & $\begin{array}{l}\chi^{2} / \mathrm{p} \\
\text { value }\end{array}$ & $\begin{array}{c}\text { No history } \\
\text { of SPIPV }\end{array}$ & $\begin{array}{l}\text { History } \\
\text { of SPIPV }\end{array}$ & $\begin{array}{c}\chi^{2} / \mathrm{p} \\
\text { value }\end{array}$ \\
\hline Arthritis & 14.3 & 33.5 & $39.13^{\mathrm{a}}$ & 10.1 & 22.8 & 30.40 & 33.6 & 18.1 & 32.64 \\
\hline Ulcers & 3.1 & 15.1 & $50.52^{\mathrm{a}}$ & 2.1 & 0.8 & 1.80 & 12.2 & 19.7 & 12.99 \\
\hline Cancer & 3.8 & 8.7 & 8.16 & 8.2 & 3.4 & 6.52 & 1.7 & 0.0 & 6.67 \\
\hline High blood pressure & 27.4 & 50.3 & $35.88^{\mathrm{a}}$ & 19.2 & 30.9 & 16.30 & 39.7 & 24.2 & 29.64 \\
\hline Diabetes & 11.9 & 12.1 & 0.09 & 3.7 & 2.3 & 1.09 & 29.6 & 4.7 & 98.24 \\
\hline Liver problems & 0.3 & 7.7 & $77.16^{\mathrm{b}}$ & 2.8 & 0.0 & 6.41 & na & na & na \\
\hline Kidney problems & 1.5 & 2.0 & 0.30 & 1.7 & 21.1 & $181.62^{\mathrm{a}}$ & 3.7 & 0.0 & 14.31 \\
\hline Stroke & 0.8 & 2.0 & 2.46 & 1.5 & 0.0 & 3.41 & 17.0 & 0.7 & $66.75^{\mathrm{a}}$ \\
\hline Asthma & 7.6 & 6.1 & 0.47 & 18.3 & 33.7 & 28.67 & 15.9 & 34.2 & 58.33 \\
\hline Lung disease & 0.3 & 0.5 & 0.12 & 1.2 & 0.0 & 2.78 & 3.4 & 2.7 & 0.40 \\
\hline Blood circulation & 2.5 & 9.4 & $22.97^{\mathrm{c}}$ & 2.2 & 11.8 & $54.19^{c}$ & 4.6 & 1.4 & 8.09 \\
\hline Sickle cell & 4.8 & 0.6 & 5.87 & 2.1 & 0.0 & 4.98 & 0.8 & 13.5 & $120.34^{\mathrm{a}}$ \\
\hline Heart trouble & 5.6 & 8.2 & 1.83 & 4.9 & 9.5 & 8.12 & 2.6 & 0.7 & 4.72 \\
\hline HIV/AIDS & na & na & na & 0.2 & 5.7 & $66.14^{\mathrm{b}}$ & 0.7 & 0.0 & 2.56 \\
\hline Glaucoma & 1.2 & 0.6 & 0.50 & 5.5 & 17.0 & 40.15 & na & na & na \\
\hline Tuberculosis & 0.6 & 0.0 & 1.01 & 0.2 & 0.0 & 0.38 & 8.0 & 0.0 & 31.98 \\
\hline Fertility problems & 4.9 & 11.0 & 10.32 & 2.2 & 25.6 & $218.42^{\mathrm{c}}$ & 13.1 & 12.0 & 0.30 \\
\hline Osteoporosis & 1.5 & 4.9 & 9.40 & 1.2 & 15.5 & $136.35^{\mathrm{a}}$ & 4.7 & 0.0 & 18.55 \\
\hline
\end{tabular}

"na" indicates there was insufficient data.

${ }_{b}^{\mathrm{a}} p<0.01$.

${ }_{p}^{\mathrm{b}} p<0.001$

${ }^{c} p<0.05$.

disorders than adults aged 18-24. This was also apparent for women with household incomes between $\$ 25,000$ and $\$ 35,999(\mathrm{AOR}=0.41, p<0.01), \$ 35,000$ and $\$ 49,999(\mathrm{AOR}=$ $0.47, p<0.01)$, and $\$ 75,000$ and higher $(\mathrm{AOR}=0.20, p<0.01)$, relative to women who earned less than $\$ 25,000$.

Table 7 presents predictors of "any" physical condition and shows that abused Caribbean women are at risk for physical health problems. Caribbean Black women who experienced SPIPV had about twice $(\mathrm{AOR}=2.07, p<0.05)$ the odds of having a physical health condition than women without a history of SPIPV. Again, third-generation women $(\mathrm{AOR}=5.10, p<0.001)$ were more prone to physical health conditions compared to their first-generation counterparts. The odds for physical health conditions also progressively increased with age. Women within the 25-34 (AOR $=4.08$, $p<0.001), 35-49$ (AOR $=7.12, p<0.001), 50-64(\mathrm{AOR}=$ $49.99, p<0.001)$, and 65 and older $(\mathrm{AOR}=94.33, p<0.001)$ age categories were at greater risk for physical health conditions compared with the younger cohort.

The odds for physical health conditions, however, were reduced with educational attainment. Caribbean Black women with a high school $(\mathrm{AOR}=0.33, p<0.001)$ and some college education $(\mathrm{AOR}=0.33, p<0.01)$ were at reduced odds for any physical health condition compared to those with less than a high school education.

\section{Discussion}

In this study, we explored the association between severe intimate partner violence (SPIPV) and an array of indicators of mental and physical health among Caribbean Black women residing in the United States. Relative to Caribbean
Black women without a history of SPIPV, those with a history of SPIPV typically had a significantly higher prevalence of mental disorders. These findings were especially evident for specific mood (e.g., dysthymia, bipolar), anxiety (e.g., panic agoraphobia, GAD, OCD, PTSD), and substance disorders (e.g., alcohol and drug dependence). Caribbean Black women with a history of SPIPV also had higher risk of suicidal ideation and attempt. These associations are largely consistent with previous studies. ${ }^{7,12-15}$

We also found higher rates of eating disorders among women with a history of violence. Consistent with the limited research in this area, ${ }^{19}$ Caribbean Black women with a history of SPIPV had higher rates of bulimia and binge eating compared to women without such history. These findings suggest that eating disorders may be a form of coping strategy employed by women who have experienced the stress of SPIPV under culturally constraining conditions. ${ }^{15}$

Differences between populations in our study were further observed for Caribbean Black women by generational status, with greater risk for bipolar, panic, alcohol abuse and dependency, drug dependency, PTSD, binge eating, any eating disorder, "any" psychiatric disorders, and suicide attempts trending higher rates among abused women within the second and third generations relative to first-generation women.

We generally found fewer associations between SPIPV and physical health conditions. Compared to Caribbean Black women without a history of SPIPV, those with a history of SPIPV tend to have higher prevalence rates of arthritis, liver problems, kidney problems, and HIV/AIDS. The specific etiology of arthritis and liver and kidney problems in the context of SPIPV is unclear, but may be associated with physical consequences of the violence. However, past studies 
Table 6. Multivariate Analysis of Associated

FACTORS OF LifETIME ANy MENTAL Disorders

OF U.S. CaribBean Black WoMen, 2001-2003

National Survey of American Life

\begin{tabular}{ccc}
\hline & Adjusted & Confidence \\
Characteristics & odds ratio & interval
\end{tabular}

Age of respondents

$18-24$

$25-34$

$35-49$

$50-64$

$>65$

1

0.88

0.55

0.10

0.20

Marital status

Married

Partnered

Sep-Div

Widowed

Never married

Education

Less than HS

HS graduate

Some college

College

1

0.55

0.92

0.36

0.87

(0.34-2.28)

$(0.22-1.38)$

$(0.03-0.31)^{\mathrm{a}}$

Household income

$<\$ 25,000$

$\$ 25,000-\$ 34,999$

$\$ 35,000-\$ 49,999$

$\$ 50,000-\$ 74,999$

$>\$ 75,000$

1

0.69

0.62

1.10

(0.21-1.44)

$(0.36-2.32)$

$(0.08-1.54)$

(0.51-1.47)

Employed status

Employed

Unemployed

Not in the labor force

Discrimination

No

Yes

1

0.41

0.47

0.58

0.20

(0.30-1.57)

$(0.28-1.38)$

(0.35-3.49)

Generation status

First generation

Second generation

Third generation

1

0.52

0.96

$(0.22-0.77)^{\mathrm{c}}$

$(0.27-0.81)^{\mathrm{c}}$

$(0.25-1.33)$

$(0.07-0.56)^{\mathrm{c}}$

1

2.03

(0.26-1.04)

$(0.53-1.75)$

Severe intimate partner violence

No

Yes

3.48

1

1.20

6.54

$(0.73-1.98)$

$(3.57-11.96)^{\mathrm{a}}$

${ }^{\mathrm{a}} p<0.001$

${ }_{p} p<0.05$.
${ }_{p}<<0.01$.

have documented lower efficacy of condom use negotiation among IPV survivors, ${ }^{23,24}$ a power differential that may place these women at increased risk of HIV and other sexually transmitted diseases. Again, there were noted differences between generations with those with a history of abuse being more likely to report poor physical health conditions. Nonetheless, there were trends showing greater vulnerability among second- and third-generation women for blood circulation concerns, kidney problems, osteoporosis, sickle-cell disease, and fertility problems.

We also found that the mental and physical health of $\mathrm{Ca}-$ ribbean Black women were influenced by their generational status in multivariate analyses. Consistent with past research on the immigrant paradox, ${ }^{25-27}$ rates of mental disorder were
Table 7. Multivariate Analysis of Associated

FACTORS OF LifETIME ANy Physical CONDITIONS

of U.S. CaribBean Black WoMen, 2001-2003 National Survey of American Life

\begin{tabular}{lcc}
\hline Characteristics & $\begin{array}{c}\text { Adjusted } \\
\text { odds ratio }\end{array}$ & $\begin{array}{c}\text { Confidence } \\
\text { interval }\end{array}$ \\
\hline
\end{tabular}

Age of respondents

18-24

$25-34$

$35-49$

$50-64$

1

$4.08 \quad(1.91-8.73)^{\mathrm{a}}$

7.12

$(3.57-14.18)^{\mathrm{a}}$

$>65$

49.99

$(24.18-103.35)^{\mathrm{a}}$

Marital status

Married

Partnered

94.33

$(24.79-358.99)^{\mathrm{a}}$

Sep-Div

1

$1.19 \quad(0.41-3.47)$

$0.95 \quad(0.43-2.09)$

Widowed

0.28

$(0.07-1.14)$

Never married

1.10

$(0.57-2.15)$

Education

Less than HS 1

HS graduate $\quad 0.33$

Some college $\quad 0.33$

College $\quad 0.55$

$(0.18-0.61)$

$(0.14-0.79)^{\mathrm{b}}$

(0.22-1.38)

Household income $<\$ 25,000$

$\$ 25,000-\$ 34,999$

$\$ 35,000-\$ 49,999$

$\$ 50,000-\$ 74,999$

$>\$ 75,000$

1

$0.57 \quad(0.31-1.06)$

$0.90 \quad(0.33-2.47)$

$1.14 \quad(0.45-2.91)$

$0.49 \quad(0.17-1.41)$

Employed status

Employed

Unemployed

Not in the labor

1

$1.16 \quad(0.48-2.75)$

$1.47 \quad(0.53-4.07)$

Discrimination

No

1

1.72

(0.86-3.44)

Generation status

First generation

Second generation

1

$2.01 \quad(0.96-4.21)$

Third generation

5.10

$(2.63-9.87)^{\mathrm{a}}$

Severe intimate partner violence

No 1

$\begin{array}{ll}\text { Yes } & 2.07\end{array}$

$(1.02-4.19)^{\mathrm{c}}$

${ }_{\mathrm{b}}^{\mathrm{a}} p<0.001$.

$p<0.01$.
$p<0.05$.

generally the lowest among first-generation Caribbean Black women, with intermediate levels among second-generation respondents, and the highest odds of having a mental disorder among third-generation (i.e., U.S.-born) Caribbean Black women. Similar to previous research, ${ }^{28}$ this was also the case for physical health problems, where the odds of health concerns typically increased among third-generation participants in this study.

There are a number of limitations that should be considered. To begin, the focus of this study was on SPIPV. The present findings may not apply to minor physical abuse or other forms of IPV (e.g., psychological, sexual) that could also have immediate or long-term health consequences. Another potential limitation to the study is the use of a single 
dichotomous measure; however, comparison of this indicator with the CTS found fair agreement with the measure. Single dichotomous items have also been used in other studies. ${ }^{29,30}$ Third, the cross-sectional study design limits our ability to draw causal inferences. For this reason, it is difficult to ascertain whether the mental and physical disorders explored in this article are the consequences of SPIPV. In some cases, the presence of these disorders (such as an episode of mania in someone who has bipolar disorder) may put women at risk for SPIPV; in other cases, it appears likely that women experience mental and physical disorders as a consequence of SPIPV.

Fourth, the relatively small sample size of women with a history of SPIPV may have played a role in our inability to detect other meaningful differences in health outcomes between the populations under examination. This might be the case for the findings elaborating the role of generational status. In addition, sample size issues prevented the examination of disorders of participants from a specific Caribbean country of origin.

Fifth, the use of the self-report of physician diagnosis indicators for physical health outcomes may bias the sample in that those with the most socioeconomic resources would be more likely to visit a healthcare professional than those with lower socioeconomic status. Similarly, there might be inaccuracy or withholding of both health status and SPIPV status information among participants, a circumstance that may especially affect undocumented immigrant women. Finally, the data used for this study were collected over a decade ago. However, this dataset is appropriate for examining the study's purpose as these relationships are not likely to change over time.

Even with the limitations outlined, this study provides important insights into the association between SPIPV and the negative mental and physical health conditions of Caribbean Black women as well as the general health of women within this population. This study additionally used a structured mental health assessment tool and doctor diagnosed health conditions to understand differences in health, which is rarely used in studies on Caribbean populations. Moreover, given that studies among this population are generally based on nonrandom clinical samples, this article provides an important contribution because it is one of very few population-based studies on U.S. Caribbean Black women. It is also one of few studies to examine generational differences in health outcomes of Caribbean Black women associated with their history of SPIPV.

As a whole, these results show that severe IPV is an important risk factor to the overall well-being of U.S. Caribbean Black women, especially with regard to their mental health. The results also suggest that second- and third-generation (i.e., U.S. born) respondents may face a heavier burden of mental disorders and physical health conditions associated with SPIPV than first-generation women who were born outside the United States. The study further suggests that social context and processes of acculturation resulting from stressful environmental circumstances might not only be associated with poorer health outcomes among abuse victims but also nonvictims in general.

These findings indicate that inquiry into women's history of IPV during a clinical encounter may have tremendous utility in pointing to potential corresponding health risks faced by this population. An important applied work particularly finds that brief screening tools in an emergency de- partment setting is effective at identifying patients at risk. ${ }^{31}$ These screening tools should also be tailored and validated for use among diverse populations of Blacks (e.g., African Americans, Caribbean Blacks, and African born); moreover, the importance of generational status is an important additional consideration. Some scholars have called for universal IPV screening in healthcare settings, ${ }^{32}$ an initiative that would help to identify Caribbean Black women who may be either currently experiencing SPIPV or suffering from the negative physical or mental health outcomes associated with a prior experience of SPIPV.

Even with needed attention surrounding the health status of women with a history of IPV, it is also important that we remain vigilant concerning the general health of immigrant women in the United States. As has been found in studies, these women are vulnerable to poorer health outcomes with longer time in host countries due to their status and social and environmental factors. Therefore, it is important that future research continues to identify factors associated with poor health with hopes of reducing the risks among U.S. Black and immigrant women.

\section{Acknowledgments}

We thank Jamie M. Abelson and Niki Matusko for their helpful insight and assistance with this article. The first author also thanks Dr. James S. Jackson for his continued support and mentorship.

\section{Author Disclosure Statement}

No competing financial interests exist.

\section{References}

1. Caetano R, Field CA, Ramisetty-Mikler S, McGrath C. The 5-year course of intimate partner violence among white, black, and hispanic couples in the United States. J Interpers Violence 2005;20:1039-1057.

2. Black MC, Basile KC, Breiding MJ, et al. The National Intimate Partner and Sexual Violence Survey: 2010 Summary Report. Atlanta, GA: National Center for Injury Prevention and Control, Centers for Disease Control and Prevention; 2011. Available at: www.cdc.gov/violenceprevention/pdf/ nisvs_report2010-a.pdf Accessed February 17, 2016.

3. Breiding MJ, Chen J, Black MC. Intimate partner violence in the United States -2010. Atlanta, GA: National Center for Injury Prevention and Control, Centers for Disease Control and Prevention, 2014.

4. Le Franc E, Samms-Vaughan M, Hambleton I, Fox K, Brown D. Interpersonal violence in three Caribbean countries: Barbados, Jamaica, and Trinidad and Tobago. Rev Panam Salud Pública 2008;24:409-421.

5. Stockman JK, Lucea MB, Bolyard R, et al. Intimate partner violence among African American and African Caribbean women: Prevalence, risk factors, and the influence of cultural attitudes. Glob Heal Action 2014;7:24772.

6. Thomas KJA. A Demographic Profile of Black Caribbean Immigrants in the United States, 2012. Available at: www .migrationpolicy.org/research/CBI-demographic-profile-blackcaribbean-immigrants Accessed July 18, 2015.

7. Dillon G, Hussain R, Loxton D, Rahman S. Mental and physical health and intimate partner violence against women: A review of the literature. Int J Fam Med 2013;2013:e313909. 
8. Devries KM, Child JC, Bacchus LJ, et al. Intimate partner violence victimization and alcohol consumption in women: A systematic review and meta-analysis. Addiction 2014;109:379-391.

9. Hien D, Ruglass L. Interpersonal partner violence and women in the United States: An overview of prevalence rates, psychiatric correlates and consequences and barriers to help seeking. Int J Law Psychiatry 2009;32:48-55.

10. Plichta SB. Intimate partner violence and physical health consequences policy and practice implications. J Interpers Violence 2004;19:1296-1323.

11. Ellsberg M, Jansen HAFM, Heise L, Watts CH, GarciaMoreno C. WHO Multi-country Study on Women's Health and Domestic Violence against Women Study Team. Intimate partner violence and women's physical and mental health in the WHO multi-country study on women's health and domestic violence: An observational study. Lancet Lond Engl 2008;371:1165-1172.

12. Golding JM. Intimate partner violence as a risk factor for mental disorders: A meta-analysis. J Fam Violence 1999;14: 99-132.

13. Stockman JK, Hayashi H, Campbell JC. Intimate Partner Violence and its Health Impact on Ethnic Minority Women [corrected]. J Womens Health 2015;24:62-79.

14. Lacey KK, McPherson MD, Samuel PS, Powell Sears K, Head D. The impact of different types of intimate partner violence on the mental and physical health of women in different ethnic groups. J Interpers Violence 2013;28:359-385.

15. Lacey KK, Sears KP, Matusko N, Jackson JS. Severe physical violence and Black women's health and wellbeing. Am J Public Health 2015;105:719-724.

16. Adler NE, Rehkopf DH. U.S. Disparities in Health: Descriptions, Causes, and Mechanisms. Annu Rev Public Health 2008;29:235-252.

17. Williams DR, Jackson PB. Social sources of racial disparities in health. Heal Aff Proj Hope 2005;24:325-334.

18. Williams DR, Collins C. Racial residential segregation: A fundamental cause of racial disparities in health. Public Health Rep 2001;116:404-416.

19. Lucea MB, Francis L, Sabri B, Campbell JC, Campbell DW. Disordered eating among African American and African Caribbean women: The influence of intimate partner violence, depression, and PTSD. Issues Ment Health Nurs 2012;33:513-521.

20. Jackson JS, Neighbors HW, Nesse RM, Trierweiler SJ, Torres M. Methodological innovations in the National Survey of American Life. Int J Methods Psychiatr Res 2004;13:289-298.

21. Heeringa SG, Wagner J, Torres M, Duan N, Adams T, Berglund P. Sample designs and sampling methods for the Collaborative Psychiatric Epidemiology Studies (CPES). Int J Methods Psychiatr Res 2004;13:221-240.

22. Pennell B-E, Bowers A, Carr D, et al. The development and implementation of the National Comorbidity Survey Re- plication, the National Survey of American Life, and the National Latino and Asian American Survey. Int J Methods Psychiatr Res 2004;13:241-269.

23. Swan H, O'Connell DJ. The Impact of Intimate Partner Violence on Women's Condom Negotiation Efficacy. J Interpers Violence 2012;27:775-792.

24. Davila YR, Brackley MH. Mexican and Mexican American women in a battered women's shelter: Barriers to condom negotiation for HIV/AIDS prevention. Issues Ment Health Nurs 1999;20:333-355.

25. Alegria M, Canino G, Shrout PE, et al. Prevalence of mental illness in immigrant and non-immigrant U.S. Latino groups. Am J Psychiatry 2008;165:359-369.

26. Takeuchi DT, Zane N, Hong S, et al. Immigration-Related Factors and Mental Disorders Among Asian Americans. Am J Public Health 2007;97:84-90.

27. Takeuchi DT, Alegria M, Jackson JS, Williams DR. Immigration and Mental Health: Diverse Findings in Asian, Black, and Latino Populations. Am J Public Health 2007; 97:11-12.

28. Lacey KK, Sears KP, Govia IO, Forsythe-Brown I, Matusko N, Jackson JS. Substance Use, Mental Disorders and Physical Health of Caribbeans at-Home Compared to Those Residing in the United States. Int J Environ Res Public Health 2015;12:710-734.

29. Flake DF, Forste R. Fighting Families: Family Characteristics Associated with Domestic Violence in Five Latin American Countries. J Fam Violence 2006;21:19-29.

30. Lacey KK, Carolyn MW, Niki M, James SJ. Prevalence and Factors Associated With Severe Intimate Partner Violence Among U.S. Black Women: A Comparison of African American and Caribbean Blacks. Violence Women 2015; 1-20. DOI: 10.1177/1077801215610014.

31. Houry D, Kemball RS, Click LA, Kaslow NJ. Development of a brief mental health screen for intimate partner violence victims in the emergency department. Acad Emerg Med Off J Soc Acad Emerg Med 2007;14:202-209.

32. Ghandour RM, Campbell JC, Lloyd J. Screening and counseling for Intimate Partner Violence: A vision for the future. J Womens Health 2014;24:57-61.

Address correspondence to: Krim K. Lacey, PhD

Program for Research on Black Americans Institute for Social Research University of Michigan 5062 ISR

426 Thompson Street Ann Arbor, MI 48106

E-mail: krimlacey@gmail.com 
This article has been cited by:

1. Natalie Jones, Christine W. Thorpe. 2016. Domestic Violence and the Impacts on African American Women: A Brief Overview on Race, Class, and Root Causes in the United State. OMNES: The Journal of Multicultural Society 7:1, 22-36. [Crossref] 